\title{
The structuring role of artificial structure on fish assemblages in a dammed river of the Pearl River in China
}

Lei Zhou ${ }^{1,2,3,4}$, Dingli Guo ${ }^{1,3,4}$, Lei Zeng ${ }^{1,3,4}$, Peng Xu ${ }^{1,3,4}$, Qindong Tang ${ }^{1,3,4}$, Zhi Chen ${ }^{1,3,4}$, Qiaoying Zhu ${ }^{1,3,4}$, Gongpei Wang ${ }^{1,3,4}$, Qiaofei Chen ${ }^{5}$, Luoan Chen ${ }^{1}$, Yong Luo ${ }^{6}$ and Guifeng Li ${ }^{1,3,4, *}$

${ }^{1}$ Guangdong Province Key Laboratory for Aquatic Economic Animals, School of Life Sciences, Sun Yat-Sen University, Guangzhou, PR China

${ }^{2}$ College of Marine Science, South China Agricultural University, Guangzhou, PR China

${ }^{3}$ Institute of Aquatic Economic Animals, School of Life Sciences, Sun Yat-sen University, Guangzhou, PR China

${ }^{4}$ South China Sea Bio-Resource Exploitation and Utilization Collaborative Innovation Center, Sun Yat-sen University, Guangzhou, PR China

${ }^{5}$ College of Life Science, South China Agricultural University, Guangzhou, PR China

${ }^{6}$ Fishery, Animal Husbandry and Veterinary Bureau of Tianyang County, Baise, PR China

Received 7 November 2017 / Accepted 28 February 2018

Handling Editor: David Kaplan

\begin{abstract}
To address the fish use patterns of artificial structures mimicking floating macrophytes deployed in a impounded tributary of the Pearl River, China, field experiments were performed from December 2014 to June 2016 using multi-mesh gillnet. The fish assemblages using artificial structures differ in terms of species richness, abundance, body size, diversity indices, and ecological traits from fish assemblages on natural barren habitats of this river. Overall, fish abundance, species richness, Shannon diversity index, and functional richness were higher at the artificial structures than at the control sites, while fish length and functional evenness was greater at the control sites in comparison to artificial structures. The introduction of artificial structures did not result in statistically significant effects on fish biomass as artificial structures attracted more individuals with smaller size. Seasonal changes of chlorophyll-a and transparency may affect the efficiency of artificial structure in harboring fishes. This study revealed that artificial structures, as synthesized habitats, are effective in acting as a "fish attractor" and an alternative tool to provide new habitats for smaller individuals in a dammed river like the Youjiang River which is a structure-less ecosystem.
\end{abstract}

Keywords: Artificial structure / artificial structure / the Pearl River / structure-less ecosystem

\section{Introduction}

Fish are an important element in aquatic ecosystems, playing an important role in primary production regulation, nutrient regeneration and cycling, and energy flow (Sarvala et al., 1998; Wu et al., 2011; Hu et al., 2014). Fish also provide a good biological indication for the health of aquatic ecosystems (Oberdorff et al., 2002; Ibarra et al., 2003).

Freshwater ecosystems may well be the most endangered ecosystems in the world. Declines in biodiversity are far greater in freshwaters than in the most affected terrestrial ecosystems (Sala et al., 2000). Freshwater environments have been largely modified by large-scale economic activities and over-exploitation of aquatic resources (Chen et al., 2012).

*Corresponding author: leapfish@163.com
Dams are one of the main anthropogenic causes of diversity loss in freshwater fishes (Dudgeon et al., 2006). There have been more than 9000 reservoirs built in the Pearl River basin since 1950s (Dai et al., 2008). Damming of rivers leads to habitat degradation, by altering the flow regime, depth, dissolved oxygen (DO), and temperature of the water (Yan et al., 2013). Furthermore, dams can cause a decrease or extinction of migratory species by blocking fish passage. Pollution, over-exploitation, and other anthropogenic activities such as the introduction of alien species have also been considered as threats to natural habitats or fish biodiversity in the Pearl River (Zhou et al., 2011; Li, 2013). These alterations bring a tremendous impact on fishes and their assemblage structure (Li et al., 2009; Tan et al., 2010; Zhou et al., 2011).

The Pearl River once harbored 385 fish species with Cypriniforms being dominant ( $\mathrm{Lu}, 1990)$. However, fish resources have decreased dramatically and biodiversity has 


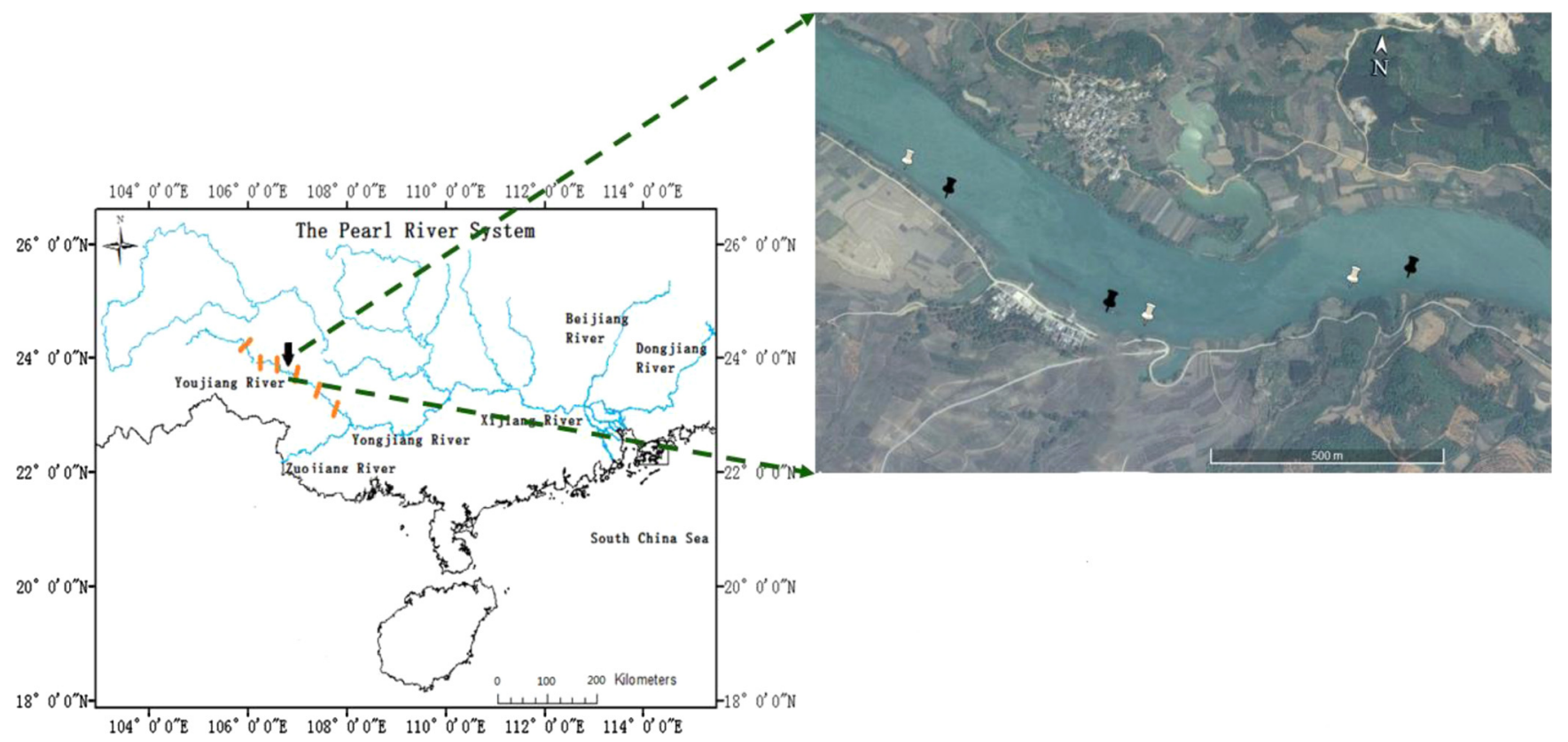

Fig. 1. Map of the study site in the Pearl River, China. Solid black arrow indicates the study site and golden bars indicate dams (Wacun Dam, Baise Dam, Dongsun Dam, Naji Dam, Yuliang Dam, Jinjitan Dam from upstream to downstream, respectively) in the Youjiang River. Black pushpins indicate the location of artificial structures and white pushpins indicate control sites. Artificial structures are also shown in the lowerright corner.

faced continuous threats over the past few decades. There is a substantial decline in fishing harvests, especially of the four major Chinese carps, i.e. black carp (Mylopharyngodon piceus), grass carp (Ctenopharyngodon idellus), silver carp (Hypophthalmichthys molitrix) and big head carp (Aristichthys nobilis) (Li et al., 2009). A total of 115 species belonging to eight orders were collected in the four tributaries (Guijiang, Youjiang, Yujiang, and Zuojiang) from 2013 to 2015, which was dramatically less than the 166 species belonging to nine orders recorded during the 1980s (Zeng et al., 2017).

The use of artificial structures has the applied potential to mitigate human-induced habitat alterations. Artificial structures are constructed to mimic some of the characteristics of a natural habitat in aquatic environments with multiple purposes such as attracting and concentrating fish (Bolding et al., 2004), enhancing fish population density (Wills et al., 2004), and offering shelter for juvenile fish (Höjesjö et al., 2015). Reservoirs are generally structure-less and lack of aquatic vegetation due to water level fluctuation (Wills et al., 2004). Artificial structures being introduced into aquatic environments could be helpful in reducing the effects of anthropogenic impacts by increasing the spatial complexity (Freitas and Petrere, 2001). According to Santos et al. (2008) approaches that use artificial structures could be helpful in mitigating the adverse impacts on fish caused by river impoundments and dam operation schemes. However, the ecological effects of artificial structures are still unclear with the existence of cascade dams in the aquatic environment and specific species composition and their general abundance in the Pearl River, China. It is essential to elucidate whether artificial structures could contribute to habitat enhancement, and what the effectiveness of these synthetic structures are in creating favorable conditions for fishes in rivers with cascade dams like the Pearl River.

In this study, we experimentally evaluated the role of artificial structures on shaping fish assemblages in the Youjiang River, a tributary of the Pearl River, China. Fish assemblage surveys were conducted seasonally from December 2014 to June 2016 by multi-mesh gillnet in combination with the monitoring of environmental variables. The purposes of this research were specifically to test if the addition of structures attracted a more abundant and/or different fish assemblage than nearby structure-less areas of a similar depth and bottom sediment.

\section{Materials and methods}

\subsection{Study area}

The Pearl River is the third largest river in China and the largest in South China, with three main tributaries-the Beijiang River, the Dongjiang River, and the Xijiang River-that all discharges into the northern part of the South China Sea (Fig. 1). The Youjiang River is a major tributary of the Xijiang River, which rises in eastern Yunnan and joins the Zuojiang River near Nanning to form the Yongjiang River. It stretches for $727 \mathrm{~km}$ and drains an area of $4.02 \times 10^{4} \mathrm{~km}^{2}$ (Zhou et al., 2011). The Youjiang River is regulated by six cascade medium/ large size dams in Wacun, Baise, Dongsun, Naji,Yuliang, and Jinjitan, with many small dam barriers (Fig. 1). Eighty fish species have been recorded in a study of the Youjiang River conducted seasonally by our research team from November 2013 to August 2015 (unpublished data). The dominant species were Hemiculter leucisculus, Toxabramis houdemeri, Oreochromis niloticus, Squalidus argentatus, Carassius auratus, 
Table 1. Environmental variables (mean $\pm \mathrm{SD}$ ) measured seasonally, from December 2014 to June 2016, at the artificial structure and control site. ODO: dissolved oxygen, TDS: total dissolved solids

\begin{tabular}{lcc}
\hline Environmental variable & Artificial structure & Control \\
\hline Temperature $\left({ }^{\circ} \mathrm{C}\right)$ & $22.415 \pm 3.402$ & $22.461 \pm 3.526$ \\
Salinity $(\mathrm{ppt})$ & $0.129 \pm 0.004$ & $0.129 \pm 0.004$ \\
$\mathrm{pH}$ & $7.75 \pm 0.37$ & $7.767 \pm 0.348$ \\
Chlorophyll $(\mathrm{ug} / \mathrm{L})$ & $5.395 \pm 3.097$ & $5.343 \pm 3.15$ \\
ODO $(\mathrm{mg} / \mathrm{L})$ & $7.398 \pm 1.175$ & $7.405 \pm 1.232$ \\
AmmoniumN $(\mathrm{mg} / \mathrm{L})$ & $0.644 \pm 0.728$ & $0.5 \pm 0.373$ \\
AmmoniaN $(\mathrm{mg} / \mathrm{L})$ & $0.031 \pm 0.045$ & $0.032 \pm 0.046$ \\
Conductivity $(\mathrm{mS} / \mathrm{cm})$ & $0.257 \pm 0.018$ & $0.257 \pm 0.019$ \\
TDS $(\mathrm{g} / \mathrm{L})$ & $0.176 \pm 0.004$ & $0.176 \pm 0.003$ \\
Transparency $(\mathrm{cm})$ & $80.19 \pm 22.288$ & $79.952 \pm 22.701$ \\
\hline
\end{tabular}

Oreochromis mossambicus, Rhinogobius giurinus, Misgurnus anguillicaudatus, Opsariicjthys bidens, and Pelteobagrus fulvidraco, with relative abundance being $19.55 \%, 13.56 \%$, $7.71 \%, 6.55 \%, 4.69 \%, 4.61 \%, 4.42 \%, 3.44 \%, 2.68 \%, 2.65 \%$, respectively.

The study site was located at $23^{\circ} 46.871^{\prime} \mathrm{N}, 106^{\circ} 39.719^{\prime} \mathrm{E}$, about $36.7 \mathrm{~km}$ downstream from Dongsun Dam and $18.5 \mathrm{~km}$ upstream from Naji dam (Fig. 1). A littoral zone was selected for deploying the artificial structures. The sites, three for artificial structures and three for matching control, were structure-less and the substrate was composed mainly of clay and sand. Each treatment was randomly assigned to each site and at a distance of at least $94 \mathrm{~m}$ between sites to minimize mutual interference. The lowest water depths of these sites were $1.5-2 \mathrm{~m}$. Environmental variables of the artificial structure and control sites are shown in Table 1. Artificial structures were deployed on 7 December 2014.

\subsection{Artificial structure}

Each artificial structure had a $10.0 \mathrm{~m} \times 1.0 \mathrm{~m}$ rectangle floating frame of about $20 \mathrm{~cm}$ diameter made of bamboo pipe (Fig. 2). There were four stakes in the four inner corners to fix the longitudinal position of the structure while it could fluctuate with water level in the vertical position. Twenty $1.0 \mathrm{~m}$ long polyethylene ropes, with two umbrella-shaped artificial macrophytes attached to each rope, were attached to the frame every $1.0 \mathrm{~m}$. The artificial macrophyte, $60 \mathrm{~cm}$ wide and $40 \mathrm{~cm}$ high, was made by a green nylon net with mesh size no more than $1 \mathrm{~cm}$. A cross of bamboo sticks was used to spread out the artificial macrophyte and also worked as a sinker.

\subsection{Fish assemblage sampling and environmental parameter measurements}

All fish were sampled with multi-mesh gillnets of $18 \mathrm{~m}$ long $\times 1.5 \mathrm{~m}$ height with mesh sizes (adjacent knots) between 6.25 and $60 \mathrm{~mm}$ of the following order: $45 \mathrm{~mm}, 20 \mathrm{~mm}, 6.25 \mathrm{~mm}$, $10 \mathrm{~mm}, 55 \mathrm{~mm}, 40 \mathrm{~mm}, 12.5 \mathrm{~mm}, 25 \mathrm{~mm}, 15 \mathrm{~mm}, 60 \mathrm{~mm}$, $35 \mathrm{~mm}$, and $30 \mathrm{~mm}$. These gillnets were distributed in close proximity to each artificial structure and control site. They were

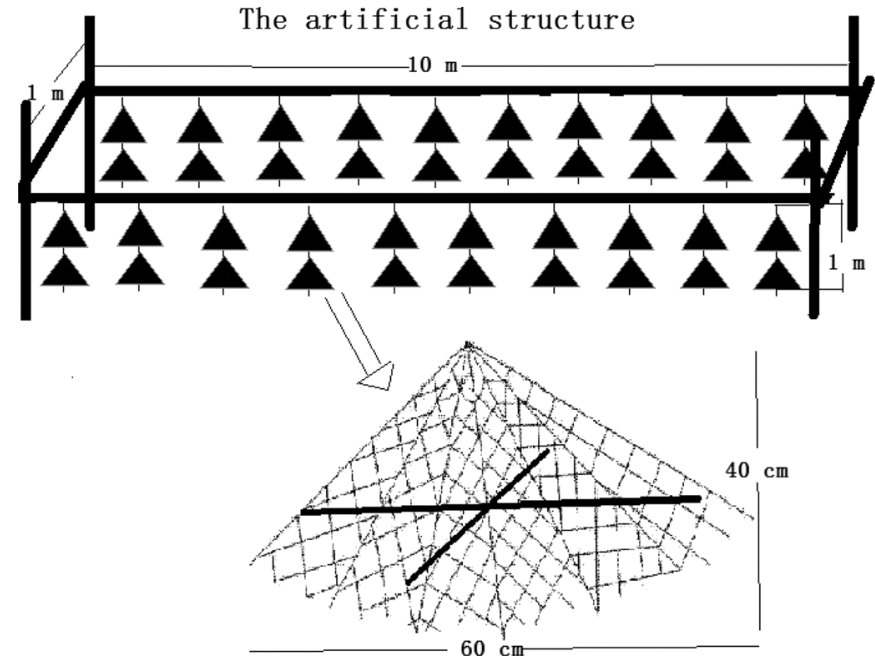

Fig. 2. The schematic diagram of artificial structure.

set in the water at 6:30-7:30 p.m. and were hauled out at 6:30 7:30 p.m. the following day. All caught fish were identified to species level, measured (body length) and weighted. Afterwards the fish still being alive were returned to the water where they were caught. Fish sampling began on 10 December 2014, three days after installation of the artificial structures, and was repeated every three months until 9 June 2016.

Measurements of environmental variables were carried out during fish collections. DO $(\mathrm{mg} / \mathrm{L})$, temperature $\left({ }^{\circ} \mathrm{C}\right)$, salinity, $\mathrm{pH}$, conductivity $(\mathrm{ms} / \mathrm{cm})$, total dissolved solids (TDS, $\mathrm{g} / \mathrm{L}$ ), ammonium $(\mathrm{mg} / \mathrm{L})$, ammonia $(\mathrm{mg} / \mathrm{L})$ and chlorophyll-a $(\mu \mathrm{g} / \mathrm{L})$ ) were measured in the middle of the water column with an YSI meter (computer module: 650 MDS, sonde: 6920; YSI Inc., Yellow Springs, $\mathrm{OH})$. Transparency $(\mathrm{cm})$ was measured using a $20 \mathrm{~cm}$ diameter Secchi disk with alternate black and white quadrants.

\subsection{Data analyses}

Fish diversity indices of each station were calculated using the sampled fish data. Given the redundancy among different diversity indices (Lyashevska and Farnsworth, 2012), we evaluated the Shannon-Wiener diversity index (Shannon and Weaver, 1949) as the measure of species diversity. We also estimated functional richness (Villéger et al., 2008), functional evenness (Villéger et al., 2008), and functional dispersion (Laliberté and Legendre, 2010) as measures of functional diversity.

Fish species were classified according to six ecological traits: (1) migratory type (sedentary, potamodromous and amphidromous); (2) habitat (pelagic, mid-water and benthic); (3) trophic guild (carnivore, herbivore and omnivore); (4) current strength preference (fast, moderate and slow-none); (5) mouth type (superior, terminal and inferior); (6) egg type (adhesive, floating, hidden, mouth brooding and spawn-inmussel egg). Hidden eggs referred to those which were spawned in hidden nests or stone gaps and spawn-in-mussel eggs referred to those which were placed into the gill of freshwater mussels by female fish such as bitterling. (1), (2), (4), and (6) were based on based on reports by $\mathrm{Lu}$ (1990), Zhou and Zhang (2006), FishBase data (Froese and Pauly, 2015); 
Table 2. Total number of individuals, biomass $(\mathrm{g})$, and average body length $(\mathrm{cm})$ of species caught at the artificial structures (AS) and control site(CS).

\begin{tabular}{|c|c|c|c|c|c|c|c|c|c|c|}
\hline Species & \multicolumn{4}{|c|}{ Total number } & \multicolumn{3}{|c|}{ Total biomass $(\mathrm{g})$} & \multicolumn{3}{|c|}{ Average body length(cm) } \\
\hline Oreochromis mossambicus & Omo & 107 & 43 & 150 & 2628 & 2218.2 & 4845.7 & 7.6 & 10.6 & 8.5 \\
\hline Oreochromis niloticus & Oni & 61 & 45 & 106 & 2743 & 3412.8 & 6156.2 & 9.6 & 11.7 & 10.5 \\
\hline Hemiculter leucisculus & Hle & 51 & 42 & 93 & 1101 & 1059 & 2159.8 & 10.9 & 12.0 & 11.4 \\
\hline Toxabramis houdemeri & Tho & 26 & 13 & 39 & 127.6 & 72.2 & 199.8 & 7.1 & 7.4 & 7.2 \\
\hline Microphysogobio fukiensis & Mfu & 16 & 5 & 21 & 56.1 & 16 & 72.1 & 5.8 & 5.7 & 5.8 \\
\hline Culter recurviceps & Cre & 10 & 5 & 15 & 262.3 & 259 & 521.3 & 12.4 & 15.7 & 13.5 \\
\hline Saurogobio dabryi & Sda & 7 & 5 & 12 & 107.8 & 19.3 & 127.1 & 10.8 & 6.7 & 9.1 \\
\hline Carassius auratus & $\mathrm{Cau}$ & 7 & 1 & 8 & 1381 & 285 & 1666.3 & 17.6 & 21.0 & 18.0 \\
\hline Rhinogobius giurinus & Rgi & 6 & 8 & 14 & 20.1 & 12.9 & 33 & 5.6 & 4.3 & 4.9 \\
\hline Pseudohemiculter dispar & Pdi & 6 & 5 & 11 & 161.6 & 140.1 & 301.7 & 12.1 & 11.9 & 12.0 \\
\hline Cultrichthys erythropterus & Cer & 4 & 0 & 4 & 306.1 & 0 & 306.1 & 17.1 & 1 & 17.1 \\
\hline Huigobio chinssuensis & Hci & 3 & 7 & 10 & 7.1 & 28.9 & 36 & 5.4 & 6.5 & 6.2 \\
\hline Ctenopharyngodon idella & Cid & 2 & 2 & 4 & 260.1 & 299.3 & 559.4 & 18.1 & 18.7 & 18.4 \\
\hline Pseudobagrus vachellii & Pva & 2 & 2 & 4 & 199.9 & 155.2 & 355.1 & 16.7 & 14.5 & 15.6 \\
\hline Pseudorasbora parva & Ppa & 2 & 2 & 4 & 12.2 & 7.2 & 19.4 & 6.7 & 5.9 & 6.3 \\
\hline Huigobio chenhsienensis & Hch & 1 & 0 & 1 & 1.5 & 0 & 1.5 & 4.4 & 1 & 4.4 \\
\hline Mystus guttatus & $\mathrm{Mgu}$ & 1 & 0 & 1 & 350 & 0 & 350 & 25.0 & l & 25.0 \\
\hline Silurus asotus & Sas & 1 & 0 & 1 & 35.1 & 0 & 35.1 & 15.1 & 1 & 15.1 \\
\hline Abbottina rivularis & Ari & 1 & 1 & 2 & 11 & 2.5 & 13.5 & 8.8 & 5.8 & 7.3 \\
\hline Squalidus wolterstorffi & Swo & 1 & 0 & 1 & 2.4 & 0 & 2.4 & 5.4 & 1 & 5.4 \\
\hline Cyprinus carpio & $\mathrm{Cca}$ & 1 & 0 & 1 & 1045 & 0 & 1045 & 33.0 & / & 33.0 \\
\hline Pelteobagrus fulvidraco & Pfu & 1 & 0 & 1 & 5.6 & 0 & 5.6 & 6.9 & 1 & 6.9 \\
\hline
\end{tabular}

(3) were based on based on reports by Lu (1990), FishBase data (Froese and Pauly, 2015) and stomach content analysis; (5) were based on our in situ observations.

Differences in ecological traits between artificial structures and controls were tested using a Chi-square test. Generalized estimating equations (GEEs) in SPSS 21.0 (SPSS Inc., Chicago, IL, USA) were used to test the impact of habitat types, sampling time and their interaction on abundance, biomass, fish length, species number, Shannon-Wiener diversity index, and functional diversity indices. GEEs are an extension of generalized linear models (GLM) in that they allow adjusting for correlations between observations (Ziegler and Vens, 2010). Additionally, following Santos et al. (2011a) principal coordinates of neighbor matrices (PCNM) vectors were embedded in GEEs to account for spatial autocorrelation.

\section{Results}

\subsection{Fish assemblage}

A total of 626 fish, amounting to $20342.6 \mathrm{~g}$, belonging to three orders, six families and 30 species, were caught over the study period (Tab. 2). In terms of fish numbers, six species each contributed $>5 \%$ and made up $76.52 \%$ of the total catch: $O$. mossambicus (23.96\%), O. niloticus (16.93\%), H. leucisculus (14.86\%), S. argentatus (8.79\%), T. houdemeri $(6.23 \%)$, Rhodeus ocellatus (5.75\%). Overall, 379 fish from 28 species were caught at the artificial structures and 247 fish from 23 species were caught at the control sites. Seven species (Cultrichthys erythropterus, Huigobio chenhsienensis, Mystus guttatus, Silurus asotus, Squalidus wolterstorff, Cyprinus carpio, $P$. fulvidraco) were recorded only at the artificial structures while two species (Xenocypris davidi and Hemibarbus labeo) were recorded only at the control sites.

Fish abundance (GEE: Wald Chi-Square $=23.2, d f=1$, $P<0.01$ ), number of species (GEE: Wald Chi-Square $=28.3$, $d f=1, P<0.01$ ) and fish length (GEE: Wald Chi-Square $=8.8$, $d f=1, P<0.01)$ varied significantly between barren habitat and artificial structure after accounting for spatial autocorrelation through PCNM. Fish abundance and number of species were higher at the artificial structures than at the control sites while fish length was greater at the control sites compared to artificial structures (Figs. 3 and 4). However, there were no significant differences in fish biomass (GEE: Wald 

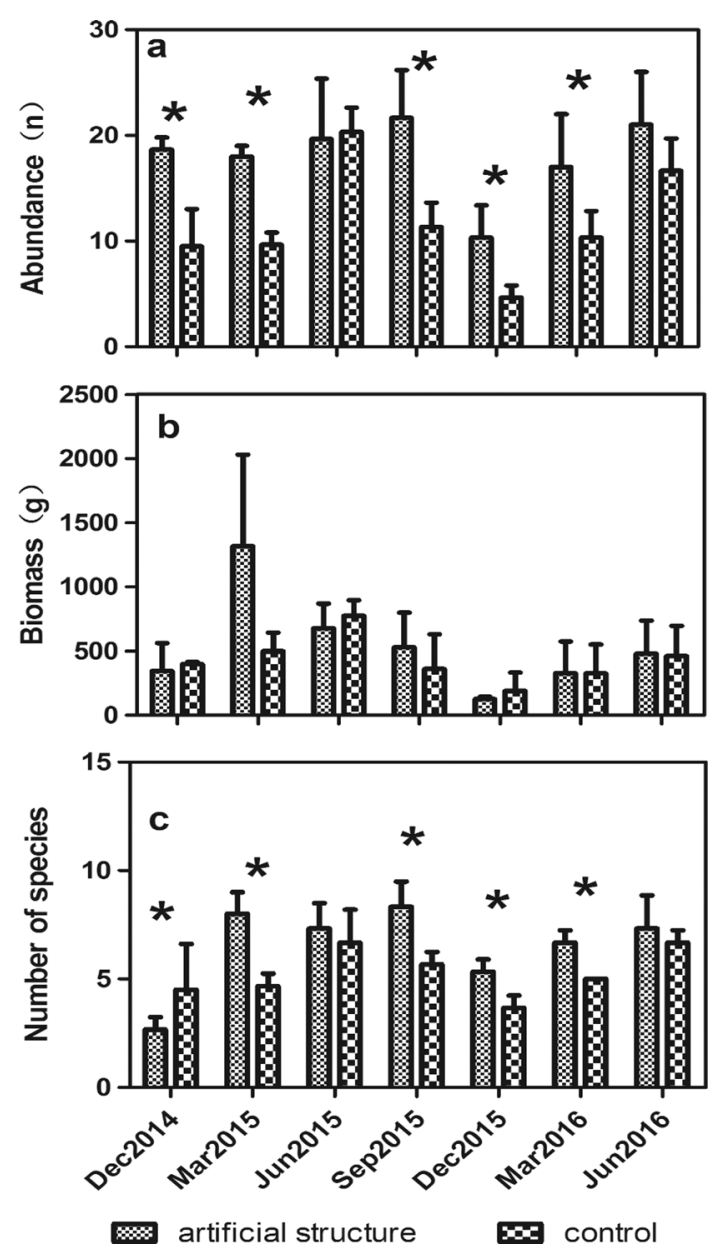

Fig. 3. Mean abundance(a), biomass(b), and number of species(c) recorded by sampling month at the artificial structure and control site. Data were expressed as mean $\pm \mathrm{SD}$, *significant between artificial structures and control sites at the 0.05 level.

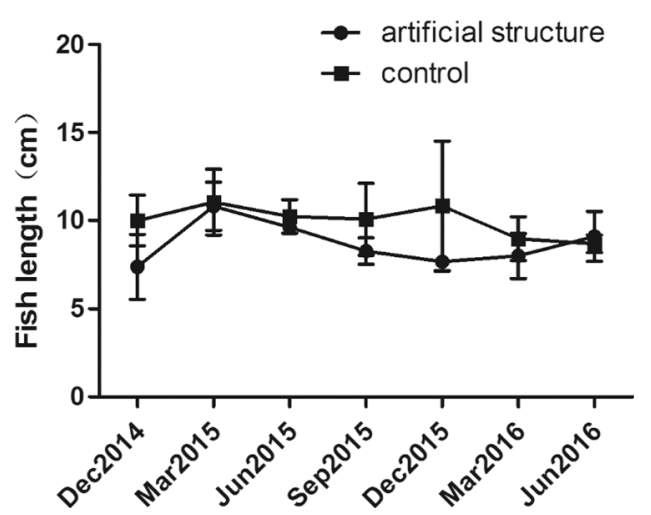

Fig. 4. Fish length recorded each sampling month at artificial structures and control sites.

Chi-Square $=2.1, d f=1, P=0.15$ ) between barren habitats and artificial structures. Changes of these community metrics through time were significant for fish abundance (GEE: Wald Chi-Square $=86.9, d f=6, P<0.01$ ), number of species (GEE:
Wald Chi-Square $=92.6, d f=6, P<0.01)$ and fish biomass (GEE: Wald Chi-Square $=38.3, d f=6, P<0.01$ ) but not for fish length (GEE: Wald Chi-Square $=10.7, d f=6, P<0.10$ ). As there were also significant site $\times$ time interactions in number of species (GEE: Wald Chi-Square $=27.5, d f=6, P<0.01)$ and fish abundance (GEE: Wald Chi-Square $=21.8, d f=6, P$ $<0.01$ ), pairwise comparisons were performed to test for differences between artificial structures and control sites per month. Differences in number of species and fish abundance between artificial structures and control sites were statistically significant for each sampling time except for June 2015 and 2016 (GEE: pairwise comparisons, $d f=6, P<0.05$; Fig. $2 \mathrm{a}$ and c). The discrepancies in average fish length between artificial structures and control sites were less in June 2015 and 2016 relative to that at other sampling times (Fig. 3).

\subsection{Diversity indices and ecological traits}

Diversity indices for artificial structures and control sites are shown in Figure 5. Shannon diversity index (GEE: Wald Chi-Square $=11.1, d f=1, P<0.01)$ and functional richness (GEE: Wald Chi-Square $=30.8, d f=1, P<0.01$ ) was significantly higher at artificial structures than those at control sites. Functional evenness (GEE: Wald Chi-Square $=12.0, d f=1$, $P<0.01)$ was significantly higher at control sites, while the functional dispersion (GEE: Wald Chi-Square $=3.1, d f=1$, $P=0.08)$ showed no significant difference between barren habitat and artificial structures.

Migratory type (chi-square $=6.565, d f=2, P=0.038$ ), habitat (chi-square $=8.151, d f=2, P=0.017$ ), mouth type (chi-square $=6.361, d f=2, P=0.042$ ), and egg type (chisquare $=11.178, \quad d f=4, \quad P=0.018) \quad$ significantly differed between artificial structures and control sites. There was no significant difference for trophic guilds (chi-square $=3.485$, $d f=2, P=0.173$ ) and water flow preference (chi-square = 1.479, $d f=2, P=0.494)$ between artificial structures and control sites (Fig. 6). In contrast to control sites, artificial structures had more fishes with ecological traits of amphidromous migration, mid-water preference, superior mouth or terminal mouth, and mouth brooding eggs.

\section{Discussion}

\subsection{Influence of artificial structures on fish assemblage}

The results showed that artificial structures had higher fish densities, species richness, Shannon diversity index, and functional richness in comparison with control sites. The results obtained are in general accordance with those of similar research focused on artificial structures in other areas of fresh water (Freitas and Petrere, 2001; Freitas et al., 2002, 2005; Santos et al., 2008, 2011a, 2011b; Gois et al., 2012), confirming that the presence of these structures induces qualitative and quantitative changes of the fish assemblages in the investigated area. Due to the close proximity of the sites, environmental variables like water temperature, salinity, $\mathrm{pH}$, chlorophyll-a, DO, ammonium, ammonia, conductivity, TDS, transparency, and sediment showed no significant differences. Therefore, the higher spatial heterogeneity of artificial structures could be a key factor to explain the comparatively 

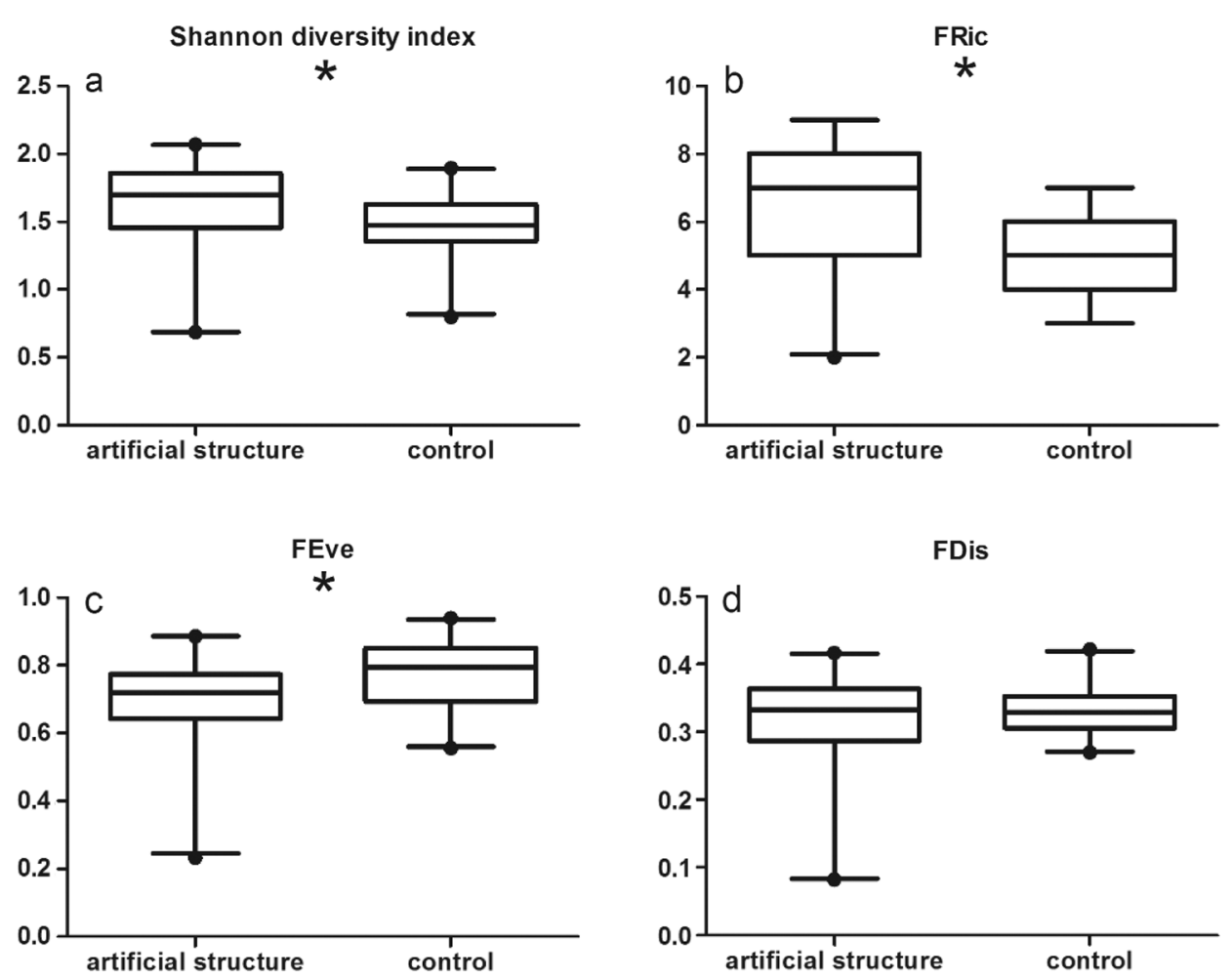

Fig. 5. Box plot of fish diversity indices at artificial structures and control sites. (a) Shannon diversity index; (b) functional richness (FRic); (c) functional evenness (FEve); (d) functional dispersion (FDis). * indicated significant between artificial structures and control sites at the 0.05 level. Whiskers: 5-95 percentile.

richer and more balanced fish assemblages as the higher complexities of the habitats might induce the formation and maintenance of richer communities (Freitas and Petrere, 2001). Physical complexity influenced fish use of habitats by providing substrata for spawning, shelter from predation or by enhancing the area for food organisms to settle on (Santos et al., 2008).

In this study, two cichlids (O. mossambicus, O. niloticus) and four cyprinidae species (H. leucisculus, S. argentatus, $T$. houdemeri, and $R$. ocellatus) dominated and consistently used the artificial structures. Cichlids have proved to be target species for evaluating the effectiveness of artificial structures on mitigating the adverse impacts on fish caused by river impoundments in Neotropical ecosystems (Santos et al., 2008; Santos et al., 2011a), which are also applicable to the subtropical river with cascade dams in our study. Artificial structure works best to concentrate structure-oriented species, and cichlids overall are characterized as fish with high dependence on submerged structures (Bolding et al., 2004; Santos et al., 2008). Reservoirs are generally structure-less and homogeneous systems as a consequence of timber removal or decay, rapid siltation of hard substrate, or lack of aquatic vegetation caused by dam operation (Wills et al., 2004). The same is true for the Youjiang River (Huang et al., 2009). Lack of submerged natural structures probably led to the high use of artificial structures by $O$. mossambicus and $O$. niloticus. Bolding et al. (2004) pointed out that the fish prevailing at the artificial structures is dependent not only on the availability of natural habitat, but also on the species composition of the fish assemblage and their general abundance in a specific area. In addition to cichlids, cyprinidae species prevailed at the artificial structures could be caused by their dominant position in the Youjiang River as mentioned in material and methods.

Seven species (C. erythropterus, H. chenhsienensis, $M$. guttatus, S. asotus, S. wolterstorff, C. carpio, $P$. fulvidraco) were recorded only at the artificial structures while two species ( $X$. davidi and $H$. labeo) were recorded only at the control sites (Tab. 2). These species have relatively low abundances in the Pearl River (Lu, 1990), indicating the potential of artificial structures for providing habitats for relatively rare species. However, the abundance of most exclusive species recorded at artificial structures is very low. A similar result was seen with artificial structures deployed in Amazonian floodplain lakes (Yamamoto et al., 2014). It may be caused by the early age and the small scale of newly submersed habitat.

The introduction of artificial structures did not result in statistically significant effects on fish biomass as the size of fish was greater at the control sites compared to artificial structures. The results confirmed that artificial structures were more effective in holding the smaller fish. Higher complexity of artificial structures relative to control sites may provide better protection from predators and available food for small fish than other less complex habitats (Santos et al., 2011b). The presence of smaller fish could also be explained by the fact that large individuals have already established territories or home-ranges while younger and smaller adults tend to be more dwelling, and could explain their presence on newly installed structures such as the artificial reefs. 

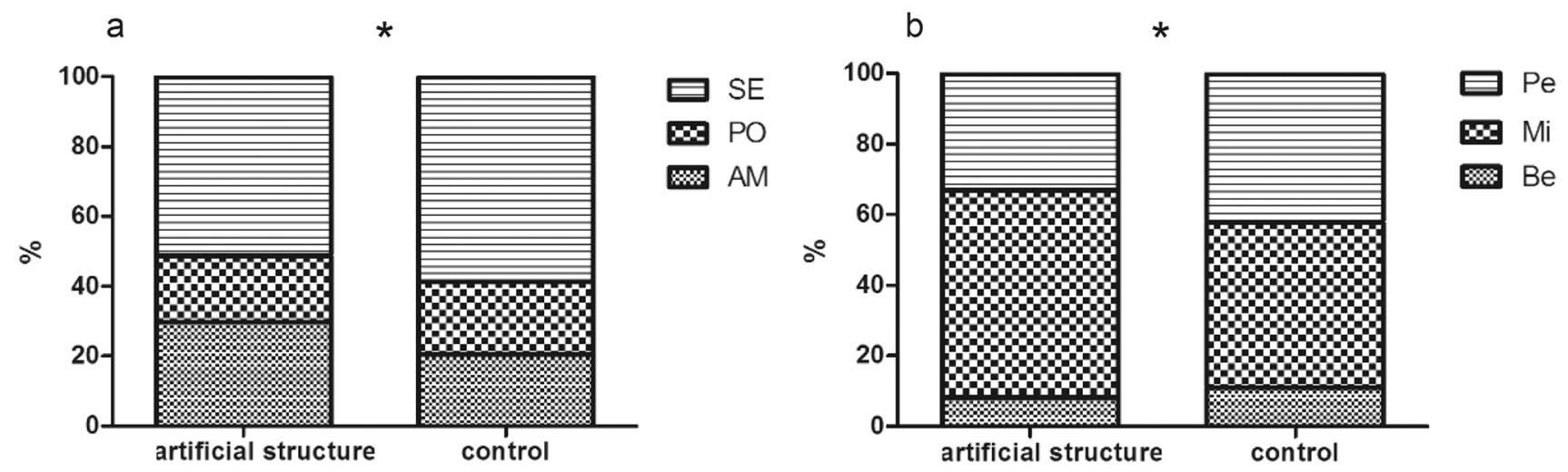

C
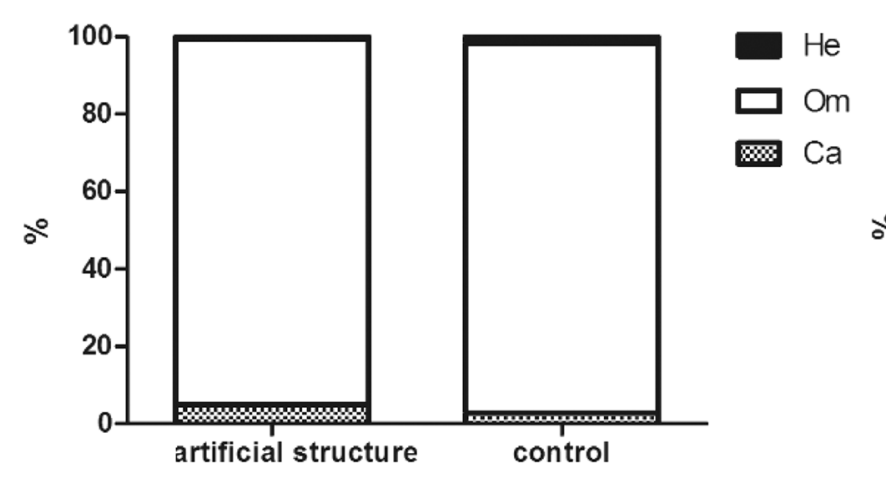

d
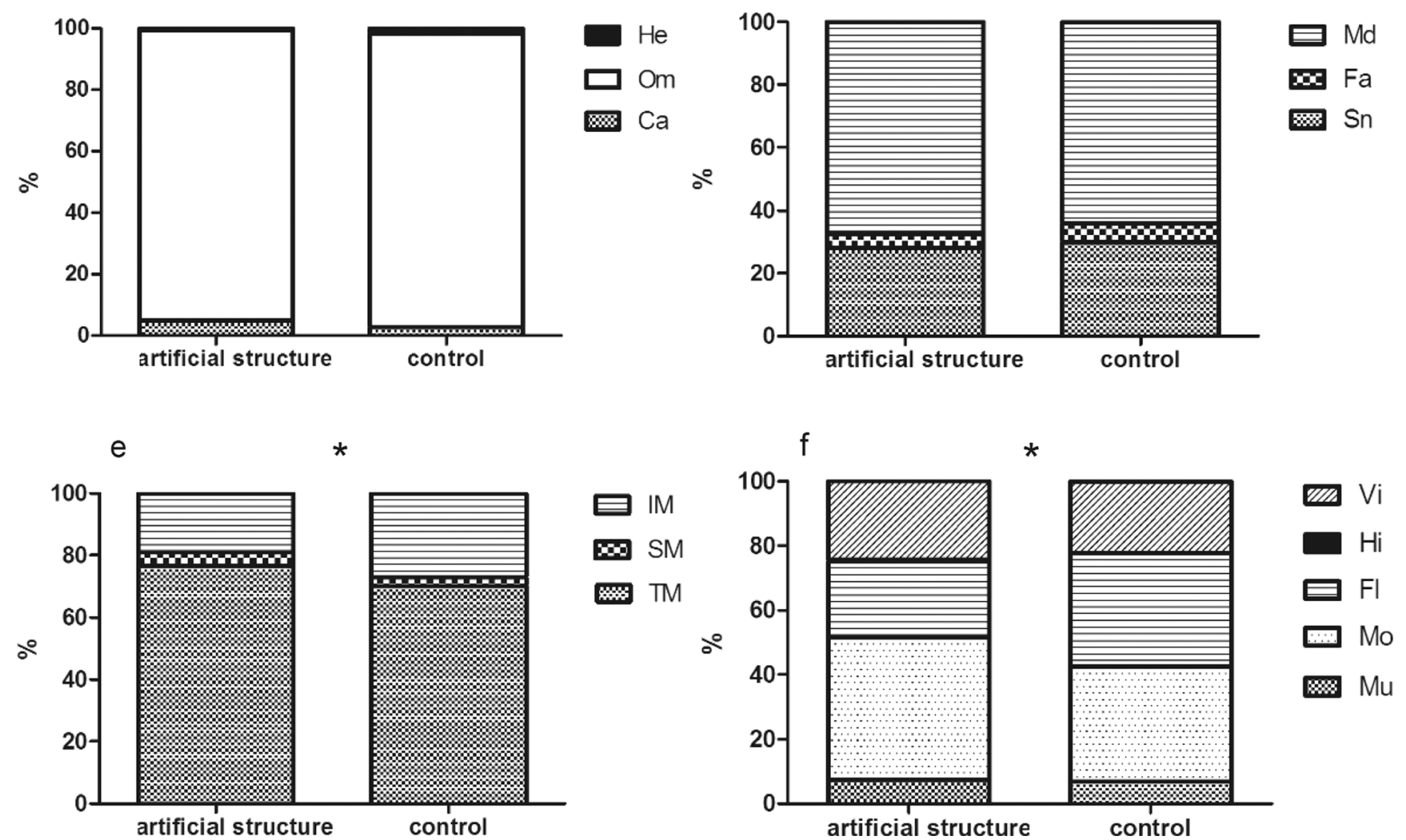

Fig. 6. Comparison of composition of ecological traits between artificial structures and control sites. (a) migratory type (SE: sedentary species, PO: potamodromous species, and AM: amphidromous species); (b) habitat (Pe: pelagic fish, Mi: mid-water fish, Be: benthic fish); (c) trophic guild (He: herbivore, Om: omnivore, Ca: carnivore); (d) (4) current preference (Fa: fast, Md: moderate, Sn: slow-none); (e) mouth type (IM: inferior Mouth, SM: superior mouth, TM: terminal mouth); (f) egg type (Vi: viscous egg, Hi: hidden egg, Fl: floating egg, Mo: mouth brooding egg, Mu: spawn-in-mussel egg). *significant between artificial structures and control sites by chi-square test at the 0.05 level.

\subsection{Utilization of artificial structures by fish with specific ecological traits}

Knowing the benefits that artificial structures can provide with respect to ecological traits is essential for determining proper management goals and developing effective ecosystem management strategies (Bolding et al., 2004). The functional organizations of fish assemblage showed significant differences between artificial structures and control sites in terms of migratory type, habitat, mouth type, and egg type in the present study, indicating the artificial structures were more effective in attracting and protecting fish with certain ecological traits. The proportions of amphidromous, midwater, superior mouth or terminal mouth, and mouth brooding fish were higher at the artificial structures while sedentary, pelagic or benthic species and fish with inferior mouth and floating eggs were more numerous at the control sites.

In contrast to most marine constructed reefs, with more resident species on the constructed reefs and more transient 
species off the constructed reefs (Bohnsack et al., 1994; Golani and Diamant 1999; Leitão et al., 2008), higher relative abundance of amphidromous species (29.82\% vs. 20.65\%) and lower relative abundance of sedentary species $(51.19 \%$ vs. $58.70 \%$ ) were observed at artificial structures in our study. It is possible that $R$. giurinus and O. mossambicus are species with an amphidromous migration strategy, that regularly migrate between freshwater and the sea (in both directions), but not for the purpose of breeding (Froese and Pauly, 2015), however the entire life cycle of the populations have to take place in freshwater due to the cascade dams in the study area. Artificial structures had been used to add additional protection by these two so-called land-locked species, and thus leading to a greater proportion of amphidromous species at artificial structures in comparison with control sites.

Different types of structures and its position have different effects on fish assemblages (Bolding et al., 2004; Santos et al., 2008). And likewise, our study suggests that ecological traits of fish assemblages mainly depend on characteristics of the artificial structure itself, such as types of structures and their location. More individual fish with midwater column preference and superior mouth or terminal mouth type were observed at the artificial structures. Those results may be determined by the middle and upper column location of the artificial structures which can provide refuge for fish preferring the same water column and increased food organisms to colonize this layer. Usually, fish with superior mouth type feed at the surface and fish having a terminal mouth are generally mid water feeders, though they can feed at any location.

$O$. mossambicus and $O$. niloticus known as the mouth brooding species (Froese and Pauly, 2015) are usually regarded as target species to test the effectiveness of artificial structures as mentioned above, leading to the result of proportionally more abundant fish with mouth brooding eggs. It should be noted that fish with hidden eggs (M. guttatus and P. fulvidraco) were only found at artificial structures. $P$. fulvidraco is a species that spawns in nests and M. guttatus in stone gaps, to hide and protect the eggs. Both of these two species are commercially important, but suffer from great threats and await protection due to environmental change and spawning ground degradation (Lu, 1990; Zhou et al., 2011).

A special mention deserves the result that fish abundance, species richness and fish length varied significantly between artificial structures and control sites, but these differences disappeared in June 2015 and 2016. The highest chlorophyll-a and the lowest transparency were detected in June which could account for this phenomenon. Lower transparency might have been used for predator avoidance that enhances survival of fishes (Whitfield, 1999) and higher chlorophyll-a, a measure of algal biomass (Matveev and Steven, 2014), means more direct or indirect food for fishes. Thus, the importance of artificial structures in providing feeding habitat and extra protection from predators for fishes was reduced in the month of June. This result confirmed that the effect of artificial structures was stronger in seasons when the water was clearer, which is in agreement with studies of artificial structures in very eutrophicated and turbid water, and in clear water (Sandström and Karås, 2002; Teixeira-de Mello et al., 2016).

\subsection{Management implication}

There has been controversy over whether artificial habitat actually produced more fish or simply serves to attract fish from elsewhere (Bohnsack, 1989; Powers et al., 2003; Santos et al., 2011a). We cannot help to solve this controversy on whether artificial structures actually increase fish production or merely redistribute fish biomass without augmenting production. But in our study, we believe a greater importance of attraction over production took place because of the physical design of the artificial structure and its relatively small size. In order to provide enough habitats to actually increase production or work as a restoration tool, the amount of structure needed would be prohibitively large. The true value for protection of juvenile fish is in providing many very small interstitial spaces in the structure, like those found in aquatic plant masses.

In conclusion, the fish assemblages in artificial structures differed in terms of species richness, abundance, body size, diversity indices, and ecological traits from fish assemblages on natural barren habitats of this river. It indicates that the artificial structures shaped fish assemblage differently because of the habitat heterogeneity and thus fish were attracted to the structure. In addition, it should be noted that the sample size of this study was small considering that more sampled fish may affected the sampling sites and results in the subsequent sampling. More treatment and control groups or longer sampling period are needed to better understand ecological effects of artificial structure before development of a largescale artificial structure program.

Acknowledgments. This research was supported by the Special Fund for Agro-scientific Research in the Public Interest (Grant No. 201303048), the National Natural Science Foundation of China (Grant No. 31772853) and the Fundamental Research Funds for the Central Universities (Grant No.16lgjc37). We would like to thank local fishermen for their help in the deployment and management of artificial structures and fish sampling, particularly Zhengzhong Long and Xiaohua Wei. Additional thanks were given to Wayne Karges, Liyun Deng, and anonymous referees who helped to revise the manuscript.

\section{References}

Bohnsack JA. 1989. Are high densities of fishes at artificial reefs the result of habitat limitation or behavioural preference? Bull Mar Sci 44: 631-645.

Bohnsack JA, Harper DE, Mcclellan DB, Hulsbeck M. 1994. Effects of reef size on colonization and assemblage structure of fishes at artificial reefs off southeastern florida, U.S.A. Bull Mar Sci 55: 796-823.

Bolding B, Bonar S, Divens M. 2004. Use of artificial structure to enhance angler benefits in lakes, ponds, and reservoirs: a literature review. Rev Fish Sci 12: 75-96.

Chen D, Li S, Wang K. 2012. Enhancement and conservation of inland fisheries resources in china. Environ Biol Fishes 93: 531545.

Dai SB, Yang SL, Cai AM. 2008. Impacts of dams on the sediment flux of the Pearl River, southern China. Catena 76: 36-43.

Dudgeon D, Arthington AH, Gessner MO, Kawabata ZI, Knowler DJ, Lévêque C, Naiman RJ, Richard AHP, Soto D, Stiassny MLJ, 
Sullivan CA. 2006. Freshwater biodiversity: importance, threats, status and conservation challenges. Biol Rev 81: 163-182.

Freitas CEC, Petrere M. 2001. Influence of artificial reefs on fish assemblage of the Barra Bonita Reservoir (São Paulo, Brazil). Lakes Reserv: Res Manag 6: 273-278.

Freitas CEC, Petrere M, Abuabara MA. 2002. Artificial reefs and their effects on fish assemblages in a Brazilian reservoir and tailrace. Ecohydrol hydrobiol 2: 305-313.

Freitas CE. Petrere CM, W. Barrella, 2005. Natural and artificiallyinduced habitat complexity and freshwater fish species composition. Fish Manag Ecol 12: 63-67.

Froese R, Pauly D. (eds), 2015. FishBase. World Wide Web electronic publication. www.fishbase.org, version (10/2015).

Gois KS, Antonio RR, Gomes LC, Pelicice FM, Agostinho AA. 2012. The role of submerged trees in structuring fish assemblages in reservoirs: two case studies in South America. Hydrobiologia 685: 109-119.

Golani D, Diamant A. 1999. Fish colonization of an artificial reef in the Gulf of Elat, northern Red Sea. Environ Biol Fishes 54: 275282.

Höjesjö J, Gunve E, Bohlin T, Johnsson JI. 2015. Addition of structural complexity-contrasting effect on juvenile brown trout in a natural stream. Ecol Freshw Fish 24: 608-615.

Hu Z, Wang S, Wu H, Chen Q, Ruan R, Chen L, Liu Q. 2014. Temporal and spatial variation of fish assemblages in Dianshan Lake, Shanghai, China. Chin J Oceanol Limnol 32: 799-809.

Huang Y, Zhou J, He A, Lu M. 2009. The ecological protection of fish resources in Guangxi Rivers. Fish Sci Technol Guangxi 3: 13-38.

Ibarra AA, Gevrey M, Park YS, Lim P, Lek S. 2003. Modelling the factors that influence fish guilds composition using a backpropagation network: assessment of metrics for indices of biotic integrity. Ecol Model 160: 281-290.

Laliberté E, Legendre P. 2010. A distance-based framework for measuring functional diversity from multiple traits. Ecology 91: 299-305.

Leitão F, Santos MN, Erzini K, Monteiro C.C. 2008. Fish assemblages and rapid colonization after enlargement of an artificial reef off the Algarve coast (Southern Portugal). Mar Ecol 29: 435-448.

Li GF. 2013. Investigation and research on freshwater fish resources of Guangdong. Science Press, Beijing, pp. 345-346.

Li J, Li X, Tan X, Li Y, He M, Luo J, Lin J, Su S. 2009. Species diversity of fish community of provincial xijiang river rare fishes natural reserve in zhaoqing city, Guangdong province. J Lake Sci 21: $556-562$.

Lu KX. 1990. Fishes and fishery resources of Pearl River system. Guangdong Science of Technology Press, Guangzhou, China.

Lyashevska O, Farnsworth KD. 2012. How many dimensions of biodiversity do we need? Ecol Indic 18: 485-492.

Matveev VF, Steven ADL, 2014. The effects of salinity, turbidity and flow on fish biomass estimated acoustically in two tidal rivers. Mar Freshw Res 65: 267-274.

Oberdorff T, Pont D, Hugueny B, Porcher JP. 2002. Development and validation of a fish-based index for the assessment of 'river health' in france. Freshw Biol 47: 1720-1734.

Powers SP, Grabowski JH, Peterson CH, Lindberg WJ. 2003. Estimating enhancement of fish production by offshore artificial reefs: uncertainty exhibited by divergent scenarios. Mar Ecol Prog Ser 264: 265-277.
Sala OE, Chapin FS, Armesto JJ, et al. 2000. Global biodiversity scenarios for the year 2100[J]. Science 287: 1770-1774.

Sandström A, Karås P. 2002. Tests of artificial substrata as nursery habitat for young fish. J Appl Ichthyol 18: 102-105.

Santos LN, Araújo FG, Brotto DS. 2008. Artificial structures as tools for fish habitat rehabilitation in a neotropical reservoir. Aquat Conserv: Mar Freshw Ecosyst 18: 896-908.

Santos LN, García-Berthou E, Agostinho AA, Latini JD. 2011a. Fish colonization of artificial reefs in a large Neotropical reservoir: material type and successional changes. Ecol Appl 21: 251-262.

Santos LN, Agostinho AA, Alcaraz C, Carol J, Santos AF, Tedesco P, García- Berthou E. 2011b. Artificial macrophytes as fish habitat in a Mediterranean reservoir subjected to seasonal water level disturbances. Aquat Sci 73: 43-52.

Sarvala J, Helminen H, Auvinen H. 1998. Portrait of a flourishing freshwater fishery: pyhäjärvi, a lake in sw-finland. Boreal Environ Res 3: 329-345.

Shannon CE, Weaver W. 1949. The mathematical theory of communication, University of Illinois press, Urbana, USA, pp. 379-423.

Tan X, Li X, Lek S, Li Y, Wang C, Li J, Luo J. 2010. Annual dynamics of the abundance of fish larvae and its relationship with hydrological variation in the Pearl River. Environ Biol Fishes 88: 217-225.

Teixeira-de Mello F, de Oliveira VA, Loverde-Oliveira SM, Huszar VLM, Barquín J, Iglesias C, Silva TSF, Duque-Estrada CH, Silió-Calzada A, Mazzeo N. 2016. The structuring role of free-floating plants on the fish community in a tropical shallow lake: an experimental approach with natural and artificial plants. Hydrobiologia 778: 167-178.

Villéger S, Mason NWH, Mouillot D. 2008. New multidimensional functional diversity indices for a multifaceted framework in functional ecology. Ecology 89: 2290-2301.

Whitfield AK. 1999. Ichthyofaunal assemblages in estuaries: a South African case study. Rev Fish Biol Fish 9: 151-186.

Wills TC, Bremigan MT, Hayes DB. 2004. Variable effects of habitat enhancement structures across species and habitats in Michigan reservoirs. Trans Am Fish Soc 133: 399-411.

Wu J, Wang J, He Y, Cao W. 2011. Fish assemblage structure in the chishui river, a protected tributary of the yangtze river. Knowl Manag Aquat Ecosyst 65: 170-181.

Yamamoto KC, de Carvalho Freitas CE, Zuanon J, Hurd LE. 2014. Fish diversity and species composition in small-scale artificial reefs in Amazonian floodplain lakes: Refugia for rare species?. Ecol Eng 67: 165-170.

Yan Y, Wang H, Zhu R, Chu L, Chen Y. 2013. Influences of low-head dams on the fish assemblages in the headwater streams of the qingyi watershed, china. Environ Biol Fishes 96: 495-506.

Zeng L, Zhou L, Guo DL, Fu DH, Xu P, Zeng S, Li GF. (2017). Ecological effects of dams, alien fish, and physiochemical environmental factors on homogeneity/heterogeneity of fish community in four tributaries of the Pearl River in China. Ecol Evol 7: 3904-3915.

Zhou H, Liu Y, Li F. 2011. Study on the fish resources of Youjiang River, Guangxi. Jiangxi Fish Sci Technol 22-25.

Zhou J, Zhang C. 2006. Freshwater Fishes of Guangxi, 2nd ed. Guangxi People's Publishing House, Nanning, China.

Ziegler A, Vens M. 2010. Generalized estimating equations. Methods Inf Med 49: 421-425.

Cite this article as: Zhou L, Guo D, Zeng L, Xu P, Tang Q, Chen Z, Zhu Q, Wang G, Chen Q, Chen L, Luo Y, Li G. 2018. The structuring role of artificial structure on fish assemblages in a dammed river of the Pearl River in China. Aquat. Living Resour. $31: 15$ 